\title{
La reescritura en colaboración: El príncipe perseguido de Luis Belmonte, Agustín Moreto y Antonio Martínez de Meneses frente a la comedia fuente El gran duque de Moscovia y Emperador perseguido de Lope de Vega*
} (Re)written in Collaboration. El príncipe
perseguido by Luis Belmonte, Agustín Moreto
y Antonio Martínez de Meneses and its Source
El gran duque de Moscovia y Emperador
perseguido by Lope de Vega

BEATA BACZYŃSKA

Universidad de Wrocław ACEPTADO: 3 DE JULIO DE 2019

Departamento de Filología Románica UWr,

PI. Nankiera 4, 50-140 Wrocław (Polonia)

beata.baczynska@uwr.edu.pl

Orcid ID 0000-0003-2777-8376

Resumen: El príncipe perseguido ofrece un interesante ejemplo de reescritura teatral. La comedia fue escrita por tres autores - Luis Belmonte Bermúdez, Agustín Moreto y Antonio Martínez de Meneses- antes del 16 de abril de 1645. Los tres dramaturgos se sirvieron de una relativamente temprana comedia de Lope de Vega, El gran duque de Moscovia y Emperador perseguido (Parte séptima, 1616). La comparación de los dos textos - la comedia colaborada y su fuente- permite conocer los modos de la escritura de consuno en el teatro del Siglo de Oro español. El análisis se concentra en el argumento (basado en la historia del falso Demetrio), que manifiesta un alto grado de compenetración a nivel macro- y microtextual entre los tres poetas. El estudio se centra en uno de los momentos más complejos en la historia de los espectáculos públicos en la España del Siglo de Oro (1644-1651).

Palabras clave: Teatro. Siglo de Oro. Lope de Vega. Calderón. Belmonte. Moreto. Martínez de Meneses. Comedia colaborada. Polonia. Moscovia. Falso Demetrio.

\footnotetext{
* Este trabajo se enmarca en lo proyecto de investigación Escritura teatral colaborativa en el Siglo de Oro: análisis, interpretación y nuevos instrumentos de investigación (Centenario de Agustín Moreto, 1618-2018), financiado por el Ministerio de Ciencia, Innovación y Universidades-Fondos FEDER, ref. FFI2017-83693-P.
} 
Abstract: El príncipe perseguido offers an interesting example of theatrical rewriting. The comedia was written by three authors -Luis Belmonte Bermúdez, Agustín Moreto and Antonio Martínez de Meneses- before 16th of April 1645. The three poets used a relatively early play by Lope de Vega El gran duque de Moscovia y Emperador perseguido (Parte séptima, 1616). The comparison of both texts -the comedia colaborada and its source- allows to investigate the modes of collaborative writing for stage in the Spanish Golden Age theatre. The analysis concentrates on the plot (based on the history of the false Dmitry) and macro- and microtextual quotes. The study refers to one of the most complex moments in the history of public theatre in the 17th century Spain (1644-1651).

Keywords: Theater. Golden Age. Lope de Vega. Calderón. Belmonte. Moreto. Martínez de Meneses. Comedia colaborada. Poland. Muscovy. False Dmitry.

E

l principe perseguido, compuesto por "tres ingenios", se ofrece como un ejemplo muy interesante de escritura de consuno y reescritura teatral. Se duque de Moscovia de Lope" (Mackenzie 61) que a la vez "presenta evidentes parecidos con La vida es sueño" (Alviti 2018, 126). La refundición corre pareja a la invención (Martínez Carro 2018, 96) manifestando un importante grado de compenetración entre los tres poetas: Luis Belmonte Bermúdez, Agustín Moreto y Antonio Martínez de Meneses. Los testimonios impresos -procedentes de Alcalá, Madrid, Sevilla, Valladolid- confirman una considerable difusión y popularidad de El príncipe perseguido hasta bien entrado el siglo XVIII. Maria Grazia Profeti (486-92) localizó en su momento más de diez sueltas diferentes, muchas de ellas en los fondos históricos de las principales bibliotecas europeas (Viena, París, Londres), algunas atribuidas a Juan Pérez de Montalbán. Sin embargo, es el manuscrito, conservado en la Biblioteca Nacional de España (con signatura Res 81), el que mejor transmite la dinámica de la escritura participativa.

EL MANUSCRITO EN EL CONTEXTO DE LA PRAXIS TEATRAL POSTERIOR A 1644

El manuscrito contiene "las grafías [...] de Belmonte, Moreto y Martínez de Meneses, pero también las del copista Sebastián de Alarcón que comparte tres páginas con Moreto en la 2. jornada" (Lobato 2015, 337) y ostenta dos "licencias de representación del célebre censor Juan Navarro de Espinosa" que "corresponden a puestas en escena separadas por cinco años", lo que permite ubicar la composición de la comedia en fechas anteriores al 16 de abril de 1645 , cuando, por un lado, su representación fue autorizada por primera vez por Navarro, y, por otro, tuvo lugar su reposición en fechas posteriores al 21 
de octubre de 1650 (Urzáiz y Cienfuegos 296). Estas dos autorizaciones inscriben la comedia colaborada en una época muy compleja en la historia del teatro áureo español.

La comedia fue escrita en vísperas de la reapertura de los corrales tras el luto por la reina Isabel de Borbón que murió el 6 de octubre de 1644. Escriben Varey y Shergold:

La prohibición habrá durado hasta la Pascua de Resurrección de 1645, pues en febrero de este año el Ayuntamiento todavía discutía el asunto en términos que indican que los teatros permanecían cerrados; en el acuerdo del 13 del mes decíase que al arrendador le habían de bajar "demas de lo que toca a los çinco meses de ymbierno que son octubre, nouiembre y diçiembre, henero y febrero, a doçe mil reales cada mes, y si el de marzo no huuiere tampoco comedias, otros doçe mil reales". Pero a 3 de abril se pregonaba un nuevo arriendo que había de correr desde el día de San Juan de 1645 hasta el mismo día de 1649 [...]. No iban a durar mucho tiempo las comedias, pues el día de Carnestolendas de 1646 se renovó la prohibición de hacer representaciones teatrales. (287-88)

Sin embargo, ya antes de que muriera la reina, a principios de 1644, el Consejo de Castilla pensaba quitar o suspender las comedias "empezando desde Pascua de Flores hasta que Dios se sirva de dar fin a las guerras tan vecinas con que Castilla se halla" (Cotarelo y Mori 1997, 164). El 1 de marzo de aquel año José de Pellicer y Tovar apuntaba comentando la decisión que tomó el Consejo: "En lo que más ahora se habla en Madrid es en las leyes que se han puesto a las comedias y comediantes. [...] En primer lugar, que no se puedan representar de inventiva propia de los que las hacen, sino de historias o vida de santos" (271). En una carta escrita ese mismo día, un jesuita informaba en detalle sobre "reformaciones en las comedias" observando al respecto: "en Madrid no se permita sino solo un autor, que había siempre de ordinario dos; que en una semana no se pueda representar sino solo una comedia nueva, que al cebo de las comedias nuevas que se hacían se llenaban los dos patios" (en Cotarelo y Mori 1997, 165).

La segunda censura de El príncipe perseguido coincide con las gestiones por parte del Ayuntamiento de Madrid para normalizar el funcionamiento de los corrales de comedias. Desde finales del año anterior, cuando llegó desde Viena la segunda esposa de Felipe Iv, la joven reina Mariana de Austria, "se iban representando comedias en Palacio, como lo demuestran varias partidas 
de papeles del Archivo de la Cofradía de la Novena, y del Palacio" (Varey y Shergold 305). Sin embargo, la situación de los corrales seguía inestable, lo que confirman dos interesantes testimonios citados por Varey y Shergold. El primero es posterior a 19 de octubre de 1650: Juan García de Albertos reclama su derecho al arriendo de los corrales alegando que "si más representaciones se permitiesen de otros autos y comedias ejemplares, hubiese de tener el útil dellas todo el tiempo que se permitiesen" (304, cursiva mía). El segundo documento es una consulta hecha a Felipe IV con fecha de 15 de febrero de 1651: "En esta Corte se ha ido tolerando el que haya comedias de historias, y en forma que el Consejo tendrá entendido [...], pues el conceder a los pueblos algún lícito desahogo parece preciso" (307). Varey y Shergold concluyen: "Las «comedias de historias» serían las «comedias ejemplares» de que hablan los documentos" (307).

¿Sería El príncipe perseguido una de aquellas comedias? Parece confirmarlo la inusual prolijidad con la que Juan Navarro de Espinosa la censura al reverso del último folio de la segunda jornada fechada "en Madrid a 21 de octubre 1650":

He visto esta comedia y, si bien es su historia humana, es tan piadosa y el caso tan decoroso y ejemplar que puede pasar por divina que El príncipe perseguido en ella es niño, y en sus adversidades se vale del asilo de San Francisco tomando su hábito, con que se libra del tirano que le persigue, siendo este el mejor paso de la comedia. Puede llamarse La inocencia perseguida y sagrado de Francisco, con que el nombre es más piadoso; y se podrá repetir segunda vez en los teatros de esta Corte. Este es mi parecer. (fol. $31 \mathrm{v}$; se ha modernizado la ortografía)

Roberta Alviti hizo un competente análisis del manuscrito en su catálogo de autógrafos de comedias colaboradas del Siglo de Oro (2006). Sus observaciones fueron comentadas en aportaciones posteriores por Alessandro Cassol (2008) y María Luisa Lobato (2015). Sin embargo, hasta ahora no se ha hecho una exhaustiva comparación de El principe perseguido con El gran duque de Moscovia y Emperador perseguido de Lope de Vega que permita entrever la dinámica de la escritura de consuno. ${ }^{1}$

1 En su tesis de máster dedicada a El príncipe perseguido Adelaida Cortijo (1998) se refiere en detalle a ambas comedias, sin embargo sus observaciones se limitan a cuestiones relacionadas con la trama e historia. 
Como ya apuntó Alessandro Cassol "la probable sesión de planificación de la pieza" se pudo hacer "con un ejemplar de la Parte VII (1616) de Lope a mano" (176). El príncipe perseguido reproduce fragmentos del texto dramático de Lope de Vega, aunque la trama sufrió sustanciales cambios que afectaron tanto a la secuencia de los sucesos, como al número y al carácter de los personajes, y -consecuentemente- al género: el drama histórico de Lope se transformó en una comedia palatina al estilo de Calderón (ver Baczyńska). Creo probable que los tres dramaturgos dispusiesen de varios y distintos ejemplares de la comedia fuente, si tenemos en cuenta, por ejemplo, el uso distinto del nombre de Juan Basilio. ${ }^{2}$

\section{LA HISTORIA DE DEMETRIO VISTA DESDE ESPAÑA}

El gran duque de Moscovia y Emperador perseguido de Lope de Vega relata la historia de Demetrio, heredero del zar Iván el Terrible (1533-1584), quien en 1605 -ayudado por tropas polacas- reclamó el trono del Gran Ducado de Moscovia usurpado por Boris Godunov. ${ }^{3}$ Aquellos sucesos fueron seguidos con gran interés en toda Europa, también en España: ya el 20 de mayo del año siguiente se dio licencia para que se imprimiera la Relación de la señalada y como milagrosa conquista del paterno Imperio, conseguida del Serenísimo Príncipe Juan Demetrio, Gran Duque de Moscovia, en el año 1605 de Juan Mosquera. Luis Iglesias Feijoo, en una aportación reciente, concluye que Lope se sirvió de este folleto y la relación comprendida en la tercera parte de Historia pontificial y católica de Luis de Bavia, publicada en Madrid en 1608, para componer una es-

2 El manuscrito autógrafo de El príncipe perseguido parece reproducir una curiosa variante que afecta a la onomástica de El gran duque de Moscovia. Milagros Villar, en su edición crítica de la comedia de Lope, constata que el Gran Duque de Moscovia "[a]parece con su nombre completo «Juan Basilio» en la lista de las dramatis personae y acotaciones del M. Y dos veces con la grafía «Iuan Basilio» en AB (vv. 266 y 2219)" (en Lope de Vega 586). Milagros Villar toma como texto base (A) la princeps de la Parte séptima (Madrid, 1617), el testigo B corresponde a la edición de Barcelona del mismo año: "una copia servil de A"; el testigo M es una copia manuscrita "[p]robablemente del siglo XVII", BNE Ms. 16673 (en Lope de Vega 466). Los autores de El príncipe perseguido podían disponer de un testimonio de la comedia fuente que pertenecía a la misma rama que el manuscrito titulado Comedia famosa de los nuevos sucesos del gran duque de Moscovia, conservado en la BNE, y disponer de algún volumen de la Parte séptima de Lope de Vega. El autógrafo de Martínez de Meneses (la tercera jornada de la comedia colaborada) se refiere al personaje de Juan Basilio con la abreviación "Bassi." y en las acotaciones accidentalmente también solo con el nombre "Basilio" (fol. 45r), mientras que Belmonte y Moreto (jornadas primera y segunda) consecuentemente utilizan la abreviación "Ju" o "Juo" para introducir sus parlamentos; en las acotaciones, respectivamente, recurren a "Juan" (Belmonte) y "JuoBasilio" (Moreto).

3 Sobre las fuentes de Lope ver, entre otros, Praag, Brody, Weiner, Lauer, Iglesias Feijoo. 
pecie de crónica dramatizada "con elementos poco frecuentes en su teatro: multitud de personajes, hechos sangrientos en escena, violencia, persecuciones, poderosos tiránicos, vesania, horror y triunfo final de la justicia" (284). La comedia El gran duque de Moscovia tuvo que ser compuesta ya en 1608, cuando los sucesos de Moscovia seguían siendo muy actuales. Es casi seguro que Lope ignorase que Demetrio fue destituido y asesinado en 1606. Recordemos que varios fueron los falsos Demetrios: en los años 1608-1610 otro falso Demetrio estuvo activo en el Gran Ducado de Moscovia; tras su muerte apareció incluso otro más.

En 1645 -cuando Belmonte, Moreto y Martínez de Meneses conciben El principe perseguido- los sucesos de los Tiempos Turbios (Smútnoie Vremia) relacionados con la sucesión de la corona en Rusia ya no tenían el aura de actualidad, más bien podían servir de ejemplo, de acuerdo con la normativa sobre las comedias, decretada el año anterior por el Consejo real, que recomendaba representar comedias "de Historia o vidas de santos" (Pellicer de Tovar I 489). María Luisa Lobato, refiriéndose a la estrategia tomada por los tres autores de El príncipe perseguido, observa:

En cuanto a si la composición [...] se hizo de forma simultánea o sucesiva, ambas posibilidades podrían darse tras un primer intercambio de ideas, como indica Alviti. Pero tampoco veo con la claridad con que ella lo afirma que, en el caso de que los tres autores escribieran uno tras otro, no conocieran el borrador de sus antecesores, pues ese hecho me parece importante para conseguir la coherencia deseada en una comedia, aunque también podría afirmarse que no es eso lo que se buscaba en aquel momento, pues, como Mackenzie indicó en las breves páginas que dedicó a esta comedia en 1993, Juan Basilio, el rey protagonista, presenta una personalidad muy diversa en cada una de las jornadas. (Lobato 2015,338 )

La coherencia de la composición de El príncipe perseguido, obviamente parte de la comedia fuente, aunque el planteamiento de la nueva comedia resulta muy diferente. Era fácil hacer el plan inicial sirviéndose de un texto dramático existente, y más en el caso de tres dramaturgos que ya habían colaborado antes. El príncipe perseguido sería, como mínimo, fruto de la tercera colaboración entre Luis Belmonte Bermúdez y Antonio Martínez de Meneses con Agustín Moreto. La primera colaborada de Moreto podría ser La renegada de Valladolid escrita de consuno con los mismos dos poetas ya en el año 1637 (ver 
Cassol 171, 176; Lobato 2015, 334; Alviti 2018, 131). Aquel año los tres participaron -junto con toda una prole de poetas y cortesanos- en las fiestas que se celebraron en la corte madrileña durante las Carnestolendas, organizadas con especial ostentación. En fechas anteriores al año 1643 colaboraron, junto con otros seis poetas, en la escritura de La mejor luna africana -un claro ejemplo de escritura festiva cortesana (Cassol 177). Los tres autores de $E l$ principe perseguido siempre actuaron en la misma secuencia, primero Luis Belmonte Bermúdez, después Agustín Moreto y Antonio Martínez de Meneses, en tercer lugar. Como si existiera un protocolo de seguimiento entre los tres poetas.

Al refundir El gran duque de Moscovia Belmonte, Moreto y Martínez de Meneses se alejaron de la comedia fuente y, consecuentemente, también de la realidad histórica. Recurrieron a motivos característicos para la comedia palatina ensalzando el amor y el honor como principal móvil de la conducta de los protagonistas. Redujeron el número de personajes (sin contar guardas y soldados) a diez personas. ${ }^{4} \mathrm{El}$ manuscrito carece de la lista de dramatis personae, cito por la prínceps -El mejor de los mejores libro que ha salido de comedias nuevas (Alcalá, A costa de Tomás Alfay, 1651): "Juan Basilio, príncipe; Demetrio, su hijo; Pepino, gracioso; Margarita, dama; Elena, dama; Laura, criada; Jacobo Mauricio, barba entrecana; Filipo, viejo; Ladislao, príncipe de Polonia; Rodulfo, embajador" (47).

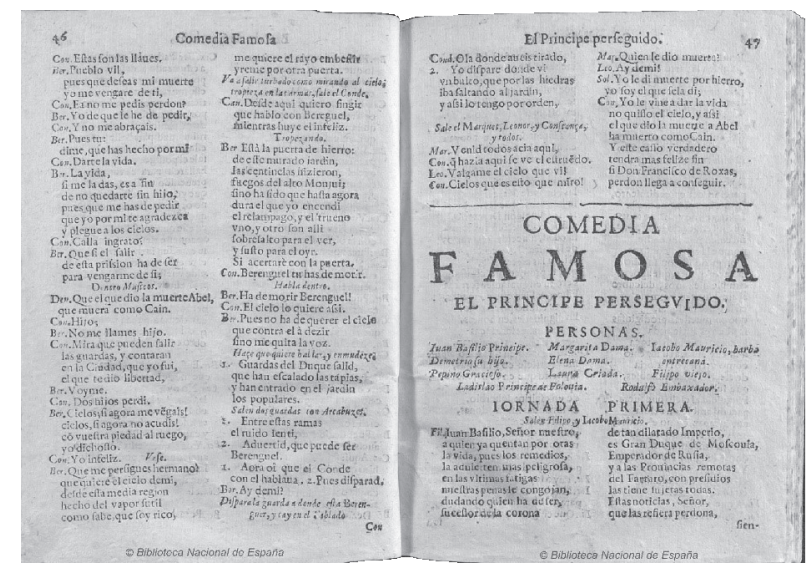

4 La prínceps de El gran duque de Moscovia enumera treinta y cuatro personas. Según la Base de Datos y Argumentos del teatro de Lope de Vega. ARTELOPE son más de cuarenta. 


\section{PERSONAS DEL DRAMA}

Solo el nombre del protagonista, Demetrio, y de su futura esposa, Margarita, corresponden con la comedia fuente. En El gran duque de Moscovia, Demetrio es nieto de Basilio, Gran Duque de Moscovia, que tiene dos hijos. El mayor, Teodoro, casado con Cristina, es el padre de Demetrio. Juan, casado con Isabela, no tiene hijos. ${ }^{5}$ En El príncipe perseguido, Demetrio es hijo del único vástago de Juan Basilio, Gran Duque de Moscovia. Juan Basilio está en el lecho de muerte y decide nombrar a su nieto, Demetrio, heredero del trono, ya que su hijo, el príncipe Juan Basilio, no está capacitado para gobernar, porque la "naturaleza [...] / le negó la generosa / porción del entendimiento" (vv. 2931). ${ }^{6}$ Hasta la mayoría de edad de Demetrio, ha de gobernar su tío, Jacobo Mauricio, cuyo nombre nos aleja aun más de la comedia fuente (Boris) y la realidad histórica (Boris Godunov).

El ayo de Demetrio no es Lamberto, un caballero alemán, que sacrifica la vida de su hijo para salvar al príncipe. Se llama Filipo y no tiene familia: no sacrifica la vida de nadie para salvar a Demetrio. Es un leal cortesano de quien, ya en la primera escena, Jacobo Mauricio pretende fiar la vil estratagema de eliminar a Demetrio y hacerse con el poder, cuando muera el Gran Duque. Sin embargo, Filipo sabe ocultar sus verdaderos sentimientos para prevenir el plan del traidor. Al final de la primera jornada abandona la corte con Demetrio fingiendo haberle ahogado en el río. En la última jornada, es él quien -en presencia del rey de Polonia- confirma la identidad de Demetrio en una emotiva secuencia, cuando Filipo -en las facciones de un joven vestido con "un grosero sayal" (v. 2556)- reconoce a su príncipe y actúa según se lo dicta el afecto y las reglas de precedencia. En El gran duque de Moscovia somos testigos de la muerte de Lamberto ya al principio de la segunda jornada. En la colaborada, el ayo de Demetrio es uno de los principales agentes de la acción a lo largo de la comedia. Filipo encarna la figura de un hombre discreto y fiel a sus principios.

En la comedia colaborada, desde el inicio de la acción, queda manifiesta la presencia del príncipe Ladislao, hijo de Segismundo, rey de Polonia, en la corte moscovita. En la comedia fuente el rey polaco es personaje secundario y

5 Lope de Vega repite el lapsus que está presente en ambas fuentes directas de su comedia; en realidad Demetrio era hermanastro de Juan y Teodoro (ver Brody 59, Iglesias Feijoo 282).

6 Cito siempre por el texto base de la comedia de Belmonte, Moreto y Martínez de Meneses, $E l$ príncipe perseguido, disponible en la página web <http://www.moretianos.com/textosbase.php>. 
no actúa hasta la última jornada, cuando el Conde Palatino le presenta a Demetrio. Segismundo, rey de Polonia, decide apoyar al príncipe a reconquistar su corona usurpada por Boris. Los autores de El principe perseguido se alejaron conscientemente de su fuente: eliminaron al Conde Palatino y ampliaron el papel del rey de Polonia, cambiando su nombre. Ladislao en la primera jornada es príncipe heredero, futuro sucesor de Segismundo, y en los actos segundo y tercero (cuya acción se desarrolla diez años más tarde) es rey de Polonia. Se trata de una referencia anacrónica a Ladislao Vasa (Władysław Waza, 1595-1648), hijo primogénito y sucesor del rey polaco, Segismundo III Vasa (Zygmunt III Waza, 1587-1632).

\section{Polonia, Moscovia y EsPaña}

Ladislao Vasa nunca estuvo en la corte de Moscovia, aunque -en 1610- su candidatura para el trono de Moscovia fue aprobada por los boyardos, cuando las tropas polaco-lituanas derrotaron a Vasili Ivanovich Shuiski quien, en 1606, había ascendido al poder como Basilio IV tras asesinar a Demetrio I el Falso. Shuiski moriría dos años más tarde encarcelado en un castillo en Polonia. El príncipe Ladislao Vasa, al ser nombrado zar de Rusia, tenía apenas 15 años. Su padre, Segismundo III Vasa, esperaba conquistar el Gran Ducado de Moscovia. Todavía en el año 1615 su secretario, Krzysztof Koryciński, reclamaba en Madrid ayuda para la guerra con Moscovia; con fecha del 15 de enero de 1615 el Duque del Infantado se pronunció al respecto en la reunión del Consejo de Estado: "es muy católico y poderoso y aunque está muy desviado de España puede hacer muchos disgustos a holandeses y diversiones de consideración en ocasiones que importen" (en Skowron 134). La tregua entre Moscovia y Polonia no se firmó hasta el año 1619, cuando la nueva dinastía -los Románov- afianzó su poder en Rusia.

Cuando Ladislao IV Vasa subió al trono de Polonia, en 1632, los contactos diplomáticos entre Varsovia y Madrid se intensificaron. ${ }^{7}$ Felipe IV quería comprometer al rey polaco "por medio de comercio y de unirlo contra Francia”, según explícitamente se informó al embajador Jean de Croy, conde de Solre, quien partió para Polonia en enero de 1635 (Skowron 165). Al año siguiente Ladislao IV Vasa confirmó que se casaría con Cecilia Renata, hija del

7 Ver Skowron (159-95). 
emperador Fernando II. El pacto de familia con los Habsburgo de Viena se firmó el 14 de diciembre de 1636. Las relaciones con Madrid tambien se estrecharon: al hermano del rey polaco, Juan Casimiro Vasa, se le ofreció el Virreinato de Portugal. Cuando el príncipe se dirigía de incógnito a España, en 1638 , fue detenido en uno de los puertos franceses del Mediterráneo y no sería liberado hasta 1641. Los españoles esperaban que Ladislao IV Vasa declarase la guerra a Francia, sin embargo, el rey polaco era lo suficientemente prudente para no hacerlo.

En 1645 la actividad diplomática entre Madrid y Varsovia tuvo un importante repunte debido a los planes matrimoniales de Ladislao IV Vasa tras la muerte de Cecilia Renata en $1644 .{ }^{8}$ Madrid quería evitar que el rey polaco se comprometiera con los franceses casándose con la princesa María Luisa de Gonzaga-Nevers. Creo probable que los tres ingenios quisiesen dar protagonismo a los polacos en su comedia debido a esas circunstancias políticas que serían notorias entre los cortesanos.

Belmonte y Martínez de Meneses eran poetas bien vinculados con la corte como ponen de manifiesto los documentos conservados en el Archivo General del Palacio Real (Martínez Carro 2006, 361-67) y también su participación en diversos eventos, en especial, la famosa Academia burlesca que se bizo en Buen Retiro a la Majestad de Filipo Cuarto el Grande año de 1637. Martínez de Meneses fue el único en participar en dicha academia con "un romance dando vejamen a los enemigos de la casa de Austria en la elección de Rey de Romanos en el señor Rey de Hungría, sin que se nombre a nadie" (Academia Burlesca 47, 195-201). El romance da fe de una buena orientación en la política exterior española del momento. Martínez de Meneses había servido en las campañas militares de la Guerra de los Treinta Años y volvió a España, desde Viena, a finales de 1633, con un singular encargo: informar a Felipe IV del nacimiento de su sobrino, hijo de la infanta María Ana y Fernando Habsburgo, rey de Hungría y Bohemia. El rey en recompensa por su servicio le hizo "merced de ayuda de guardajoyas de la Reina" (Martínez Carro 2006, 25 y 361).

8 En los años 1638-1647, los intereses de Polonia en Madrid los representaba Stanisław Mąkowski, quien durante su estancia en la capital de España dirigió más de 220 cartas y memoriales al rey Felipe IV y funcionarios de la Corona, y recibió más de 120 "consultas, decretos, resoluciones y otros despachos dados por orden de S.M. Católica y sus Consejos” (Skowron 172). 


\section{LADISLAO, PRÍNCIPE Y REY DE POLONIA}

Ladislao es presentado en la jornada primera como galán y príncipe interesado en un doble enlace dinástico para garantizar una buena relación entre Polonia y Moscovia. Piensa disponer los detalles de su matrimonio con Elena, hija de Jacobo Mauricio, y el "de Margarita, / su hermana [...] con Demetrio, / niños los dos" (vv. 71-74). Aunque viene a concretar dos bodas, termina tomando parte en un funeral al morir el Gran Duque de Moscovia. El ceremonial en la corte de Moscovia es el mismo que el de la Casa de Austria en Madrid:

\section{Suena rumor de alabardas}

[ELENA] Mas, ¿de qué es tanto rumor?

Demetrio ¡Cielos!, la guarda se muda a mi cuarto.

LADISLAO Ya sin duda murió el Duque.

DEMETRIO ¡Qué dolor! (vv. 570-73)

Se trata, en este caso, de una redondilla añadida -de puño y letra de Moretoen el margen izquierdo del folio núm. 10v correspondiente a la jornada primera escrita por Belmonte.

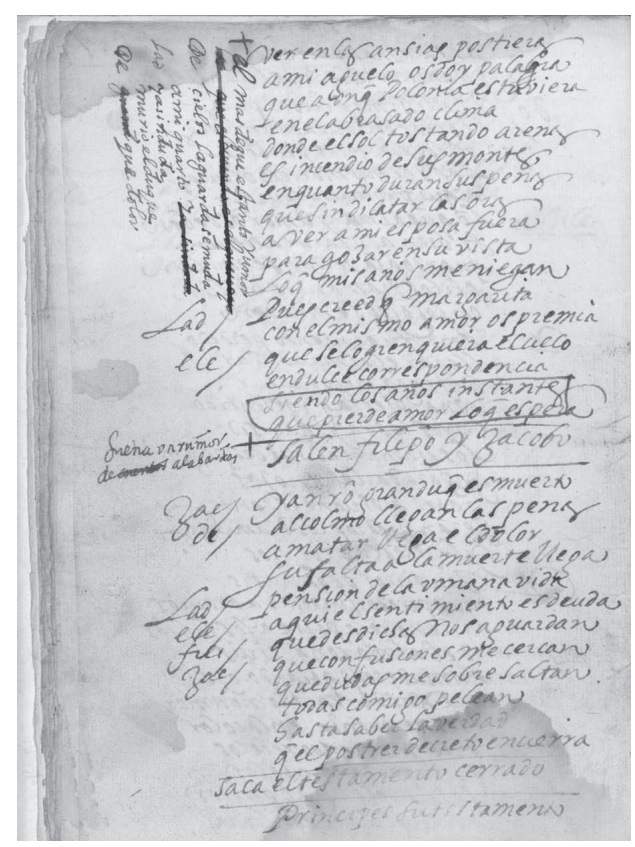


La comedia reproduce el protocolo de la corte madrileña donde los alabarderos eran las "guardias de Palacio" (Aut.):

En expirando los reyes, los capitanes de las guardias, si se hallaban presentes, y si no los oficiales de más graduación, mudaban el cuerpo de guardia a la cámara del sucesor. El presidente del Consejo de Castilla, el mayordomo mayor y el sumiller de corps llevaban el testamento cerrado al príncipe heredero y le pedían licencia para abrirlo. (Rodríguez Villa 151)

El príncipe polaco Ladislao desempeña en la primera jornada un papel fundamental. Es testigo y a la vez maestro de ceremonia en los actos de investidura de Demetrio, cuando se hace público el testamento de Juan Basilio, Gran Duque de Moscovia. Ladislao le ofrece a Demetrio un caballo para su entrada regia y dice:

\begin{tabular}{|c|c|}
\hline LADISLAO & $\begin{array}{l}\text { Y entre tanto que se apresta } \\
\text { vuestro aplauso, reconozcan } \\
\text { leal y humilde obediencia } \\
\text { besándoos la mano todos } \\
\text { los que en palacio os desean } \\
\text { con dichosa sucesión } \\
\text { la vida. (vv. 629-35) }\end{array}$ \\
\hline
\end{tabular}

Ladislao se refiere a la ceremonia de besamanos anticipando la escena que sigue. El acto de juramento de obediencia siempre precedía la entrada pública del soberano y respetaba el estricto orden de precedencia (Chiva Beltrán 219).

\section{Vuelven una silla}

Ladislao Sentaos, Príncipe.

DEMETRIO Señor,

¿cómo ha de estar Vuestra Alteza?

LADISLAO En pie debo estar yo agora, mientras que la mano os besan. (vv. 644-47)

Las referencias a la etiqueta cortesana son una constante en las tres jornadas. En la segunda, el Capitán instruye a Juan Basilio, padre de Demetrio, sobre cómo ha de saludar al rey de Polonia. El príncipe toma las indicaciones al pie de la letra y en vez de hacerle la debida reverencia quitándose a sí mismo el sombrero, se lo quita de la cabeza a Ladislao, provocando consternación entre los asistentes. Sin embargo, Ladislao le corresponde cortésmente y propo- 
ne que los dos intercambien sus sombreros. Se trata de un cuadro escénico muy vivo y -a través de los versos partidos y apartes- perfectamente construido. La secuencia la concluye Juan Basilio con un comentario metateatral que incluye una didascalia implícita y un aparte:

$$
\begin{aligned}
\text { JUAN BASILIO } & \text { Señor, llegad a mis brazos } \\
& \text { como está en la ceremonia. } \\
& \text { ([Ap] Estos reyes de Polonia } \\
& \text { son grandes cortesanazos.) (vv. 1383-86) }
\end{aligned}
$$

En la tercera jornada, Martínez de Meneses hace a Filipo suspender la "debida reverencia" (v. 2543) al rey de Polonia, Ladislao, y dirigirse primero a su legítimo y natural señor, el príncipe Demetrio:

FILIPO Por que dejéis de extrañaros

en suspensión semejante

de que no paso adelante,

la disculpa intento daros,

por quien sois iba a pagaros

con debida reverencia,

pero la real presencia

de mi natural señor,

como primer acreedor,

me ha embargado la obediencia. (vv. 2538-47)

Se tiene la impresión de que la comedia colaborada pudo ser pensada principalmente para el público cortesano, ya que en repetidas ocasiones sus autores remiten a cuestiones relacionadas con la precedencia y el comportamiento en presencia del rey.

\section{UNA EJEMPLAR COMEDIA DE HISTORIA}

El príncipe perseguido cuida al máximo del decoro. Se eliminaron todas las escenas violentas, tan impactantes en la comedia fuente, porque afrentaban la integridad del soberano: la bofetada que el Gran Duque le propina a Isabela, su nuera; el golpe mortal con el bastón que provoca la muerte de su hijo y heredero, el príncipe Juan; el estrangulamiento del niño que los ejecutores enviados por Boris creen ser Demetrio; la muerte de Lamberto; el suicidio de Boris y el de su esposa. Todos esos sucesos representados por Lope de Vega en El gran duque de Moscovia, como si fuera una chronicle play shakespeariana, co- 
rresponden al pie de la letra a hechos relatados por las crónicas del momento (Brody, Iglesias Feijoo).

Fue eliminado también todo rasgo de misoginia. En la comedia de Lope son las nueras del Gran Duque, Isabela y Cristina, las que maquinan los planes secretos de poder: rivalizan entre sí sirviéndose de sus parientes y cortesanos. Tampoco Margarita, la hija del Conde Palatino, que corresponde a la histórica Marina Mniszech, futura zarina, resulta agradable cuando ironiza sobre los planes de Demetrio que trabaja como ayudante en la cocina del palacio. En la comedia colaborada figuran dos damas y una criada, las tres de conducta impecable. Elena, hija de Jacobo Mauricio, es desde la primera jornada prometida de Ladislao, príncipe de Polonia. El príncipe había venido a la corte de Moscovia en calidad del embajador del rey de Polonia para ofrecer -en nombre de su padre- la mano de su hermana Margarita a Demetrio, a quien le traía una joya con el retrato de la dama como símbolo de la futura relación.

En la segunda jornada la princesa polaca Margarita actúa imperativamente instando a su hermano a que defienda los derechos de su prometido, Demetrio, al conocer tan solo los indicios de la usurpación del poder por parte de Jacobo Mauricio, quien insiste en que el príncipe Juan Basilio renuncie al reino en favor de Elena:

$\begin{array}{ll}\text { JaCOBo Mauricio } & {[\ldots] \text { viva Demetrio o no, }} \\ & \text { me han puesto el cetro en la mano. } \\ \text { Margarita } & \text { Pues, Ladislao valeroso, } \\ & \text { ¿cómo este agravio has sufrido, } \\ & \text { tan indigno de tu oído, } \\ & \text { siendo Demetrio mi esposo? } \\ & \text { Viviendo él, ¿quién mereció } \\ & \text { corona tan eminente? } \\ & \text { ¿o quién la tendrá en la frente } \\ & \text { más dignamente que yo? (vv. 1473-82) }\end{array}$

También Elena, segunda dama de la comedia, hija de Jacobo Mauricio, es muy independiente y valiente. En la tercera jornada, ayuda a Juan Basilio a abandonar la torre en la cual su propio padre, Jacobo Mauricio, había encarcelado al legítimo heredero del Gran Ducado de Moscovia.

Valga subrayar que El príncipe perseguido, en la figura del padre de Demetrio, retoma el motivo del príncipe encarcelado de La vida es sueño calderonia- 
na. Ann L. Mackenzie, en su estudio dedicado a "la técnica de componer comedias en colaboración", observó al respecto:

Juan Basilio [en la tercera jornada] tiene poco en común con la persona trazada por Moreto en el acto anterior. Tampoco nos recuerda la figura de Juan Basilio tal como está caracterizada en el acto primero por Belmonte. Más bien parece ser un tipo de Segismundo convertido en hombre mayor, trayéndose a la memoria al protagonista de la parte final de La vida es sueño en que, después del desengaño de su vuelta a la torre, el príncipe se muestra más prudente y filosófico. Encerrado en la cárcel, el Juan Basilio del tercer acto se alegra de que, ya viejo, tiene la prudencia que le faltaba en la juventud. (44)

\section{Juan Basilio y TeOdoro, PRíncipes de Moscovia}

La coherencia del personaje de Juan Basilio se fundamenta en el motivo del loco cuyos (1) juicios pueden resultar admirables y atisbar la cordura, y (2) a quien las penas lo vuelven cuerdo en concordancia con el refrán "El loco por la pena es cuerdo" (Aut.). Se trata de uno de los temas claves de la comedia colaborada que los tres ingenios tuvieron muy presente cuando componían $E l$ príncipe perseguido. El planteamiento basado en el binomio locura-cordura lo tomaron de Lope de Vega, quien en los primeros versos de El gran duque de Moscovia enfrenta a Basilio con "el príncipe Teodoro, mentecato":

BASILIO

Monstruo de naturaleza,

hijo en mal punto engendrado, indigno de la grandeza

de mi generoso estado;

vil, fabulosa cabeza,

[...] ¿quién en cosas graves

mete a un hombre sin razón

y discurso natural? (El gran duque de Moscovia, vv. 1-27)

Teodoro es protagonista de la exposición de El gran duque de Moscovia. A uno de los caballeros que lo asisten se le escapa un singular aparte: "Cosas dice que me admira" (v. 186). A continuación somos testigos de una interesante escena con el sastre, que Belmonte aprovecharía en la primera jornada de El príncipe perseguido: ${ }^{9}$

9 En la cita se subraya el texto reproducido en El príncipe perseguido. 
Conrado Aquí está el sastre.

TEODORO

¡Oh, maestro!

Siéntate aquí.

CONRADO Señor, mira...

Teodoro Callad, todo el trato nuestro es arrogancia y mentira.

Quién viste a un toro del cuero, de escama al pez, pluma al ave, para su curso ligero?

SASTRE Naturaleza que sabe; y ella fue el sastre primero.

Teodoro Pues si tiene tanto nombre, quien viste con tal primor un animal, no es asombre que le merezca mejor el sastre que viste al hombre. Siéntate.

SASTRE Señor, yo estoy como debo estar. (El gran duque de Moscovia, vv. 187-202)

En El principe perseguido, esta escena la relata in extenso el gracioso Pepino que adquiere aun más protagonismo que Rufino en la comedia fuente. Insiste en lo paradójico de la actuación del príncipe Juan Basilio anticipando su primera aparición en escena:

PEPINO lo que más me asombra que diga entre sus delirios razones tan ingeniosas, que lo simple se enmudece y lo cuerdo se equivoca. Entró el sastre y él le dijo:

"Vengáis, maestro, en buen hora, Sentaos"; replicaron todos, viendo una acción tan impropia de la alteza y majestad, alborotose de forma que no paró hombre en la sala, pero más templado agora se está vistiendo. (vv. 126-39) 
Belmonte, a continuación, en el diálogo entre Juan Basilio y Filipo introduce dos quintillas de Lope (ver arriba, vv. 191-200):

\section{Dentro fuan [Basilio]}

JUAN BaSiLIO Mucho es lo que el mundo ignora.

Sale vistiéndose con criados y músicos

PEPINO Ya sale.

JACOBO MAU. Señor, no adviertes...

JUAN BASILIO Vuestra rudeza pregona

vuestra ignorancia.

FILIPO

Si al sastre

le mandas sentar...

JUAN BASILIO

$$
\text { ¿Y es cosa }
$$

tan ajena de razón

siendo tan justa y tan propia?

¿Quién viste al toro del cuero,

de escama al pez, pluma al ave

para su curso ligero?

FILIPO Naturaleza que sabe,

ella fue el sastre primero.

Juan Basilio Pues si tiene tanto nombre

quien viste con tal primor

a un animal, no os asombre

que le merezca mejor

el sastre que viste al hombre. (vv. 154-70)

Por otro lado, no es casual que el cuadro escénico en el cual Juan Basilio hace acto de presencia, podríamos decir, vistiéndose, recuerde a la primera aparición del príncipe Segismundo en el palacio del rey Basilio de La vida es sueño. Los tres ingenios, al proponerse la reescritura de El gran duque de Moscovia, tuvieron claro que la comedia que componían había de imitar de una manera ingeniosa los pasos de la comedia más emblemática de Calderón, cuyos ecos se encontraban por doquier, no solo en la obra dramática de su autor. Como si quisieran que se reconociesen versos y motivos calderonianos, y que los reconociese Calderón a quien los tres conocían. Martínez de Meneses tenía trato de amistad con los hermanos Diego y Pedro Calderón según ha demostrado Elena Martínez Carro $(2006,26)$. Por otro lado, recordemos con Cruickshank (305-07) que 
Moreto hizo de Abel en la comedia de repente La creación del mundo, en la cual a don Pedro le tocó el papel de Adán. Según conjetura Cotarelo y Mori (2001, 183) la representación se hizo en Carnestolendas del año 1637.

\section{JuAN BASILIO y SEgISMUNDO, PRÍNCIPES ENCARCELADOS}

En El príncipe perseguido, Moreto parece imitar "al revés" el enfrentamiento entre el Segismundo y Astolfo calderonianos, cuando Juan Basilio, príncipe de Moscovia, le quita el sombrero a Ladislao, rey de Polonia. La relación intertextual se hace aun más explícita en la escena en la cual Juan Basilio, antes de ser llevado a la prisión por los soldados, pronuncia:

$$
\begin{array}{ll}
\text { JUAN BASILIO } & \text { ¿Cómo, amigos, no os provoco? } \\
& \text { ¡Vuestro príncipe soy yo! } \\
\text { CAPITÁN } & \text { Príncipe, sí; nuestro, no, } \\
& \text { que nadie obedece a un loco. } \\
& \text { Vanse } \\
\text { JUAN BASILIO } & \text { ¿Qué es esto, cielos? ¿Qué oí? } \\
& \text { ¿Yo abatido? ¿Yo ultrajado? } \\
& \text { ¿Yo por loco deshonrado? } \\
& \text { ¿Tan loco soy? ¡Ay de mí! } \\
& \text { En todo, en todo el sentido } \\
& \text { correr siento un vivo fuego, } \\
& \text { un mudo, habló y miró, un ciego } \\
& \text { de un grave dolor herido. } \\
& {[\ldots . .]} \\
& \text { ¡Penas llegadme a apurar!, } \\
& \text { pues me mejoro por vos, } \\
& \text { sin duda es cosa de Dios } \\
& \text { el trabajo y el pesar. } \\
& \text { Pues en Él, ya con mi acuerdo, } \\
& \text { la luz providente toco, } \\
& \text { que a un cuerdo le vuelva loco } \\
& \text { y a un loco le vuelva cuerdo. (vv. 1551-1602) }
\end{array}
$$

Hasta ahora la crítica ha subrayado la deuda de Martínez de Meneses para con Calderón en la manera en la cual explota el motivo del "príncipe encarcelado" 
en la jornada tercera de El principe perseguido. Juan Basilio pronuncia un monólogo que hace eco del primer soliloquio de Segismundo calderoniano y su famosa sentencia "el delito mayor / del hombre es haber nacido" (La vida es sueño, vv. 111-12):

\begin{tabular}{|c|c|}
\hline JUAN BASILIO & $\begin{array}{l}\text { ¡Qué ociosamente he vivido! } \\
\text { Si el ser consiste en saber, } \\
\text { quien tan ignorante ha sido } \\
\text { que nació para no ser, } \\
\text { ¿de qué sirve haber nacido? } \\
\text { Siendo para efectos tales } \\
\text { incapaz, no hay distinción } \\
\text { del hombre a los animales, } \\
\text { aun de más provecho son } \\
\text { los mismos irracionales. } \\
\text { Su piel el bruto lunado, } \\
\text { curtida del sol y el viento, } \\
\text { para que nos calce, (vv. 2740-51) }\end{array}$ \\
\hline
\end{tabular}

Marta Piłat-Zuzankiewicz, hispanista polaca, analizando la lectura emblemática de El príncipe perseguido, escribe sobre este "largo soliloquio, de evidente inspiración calderoniana":

Estas reflexiones del príncipe demuestran que [...] toma conciencia de los valores y normas que rigen la convivencia humana. [...] gracias a la observación de la naturaleza llega a conocer y comprender su profundo significado didáctico y moralizante. Así, el comentario poético de las propiedades naturales del buey, oveja, gusano de seda y abeja se convierte en una espléndida lección de virtudes. (2016, 358-60)

La asociación con La vida es sueño es más que evidente. Sin embargo, el topos de la naturaleza en cuanto maestra está presente ya en El gran duque de Moscovia ("Naturaleza, que sabe", v. 194) y -es más- corresponde a las dos quintillas que Belmonte decidió copiar en la primera jornada de la comedia colaborada, como si quisiera pagarle un tributo a Lope de Vega con la cita: “¿Quién viste a un toro del cuero, / de escama al pez, / pluma al ave, / para su curso ligero? [...]". Se trataba de un lugar común de la época áurea. Sin embargo, esa coincidencia no parece fortuita. Y más, tratándose de autores tan activos en la vida literaria y teatral de la Villa y Corte. 


\section{MicroteXTos}

Moreto -como Belmonte- también reproduce microtextos tomados directamente de la comedia fuente. Se trata de las escenas relacionadas con la estancia de Demetrio en el monasterio en las cuales interviene Pepino. Se nota una clara tendencia a potenciar lo cómico, como en la siguiente escena que manifiesta la resignación de Pepino frente a las obligaciones de fraile lego:

Sale Rufino de fraile lego, con dos escobas, a lo gracioso

[...]

\section{DEMETRIO Barre y calla.}

RUFINO Barreré, consolado en que las leyes del mundo a los altos reyes ponen en el cuello el pie. Pues barre un rey, ¿qué atropellas tiempo, en un pobre español? (El gran duque..., vv. 1333; 1356-61)

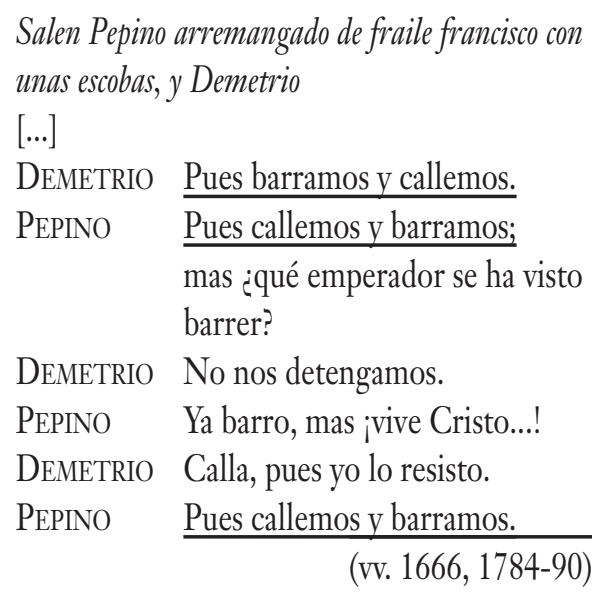

Pepino con Demetrio acaban de discutir sobre el carácter de la vida conventual, Moreto potencia el valor metateatral y didascálico del diálogo por medio de la repetición. Una modificación parecida del microtexto, típica para la técnica de reescritura en Moreto, presenta el siguiente fragmento:

\begin{tabular}{|c|c|c|c|}
\hline \multirow{3}{*}{$\begin{array}{l}\text { BORIS } \\
\text { DEMETRIO }\end{array}$} & Padre, encomiéndeme a Dios. & JACOBO MAU. & $\begin{array}{l}\text { ( }[A p] \text { Parece un santo y parece } \\
\text { el mismo.) }\end{array}$ \\
\hline & y no pasa día ninguno & PePINo & $\overline{\text { [A Demetrio] }}$ Olido nos han. \\
\hline & que no me acuerdo de vos. & JACOBO MAU. & Vaya, encomiéndeme a Dios. \\
\hline ODIC & $\underline{\text { (Parece un santo..., y parece }}$ & DEMETRIO & $\underline{\text { Con mis ruegos le importuno }}$ \\
\hline ROFRISA & $\frac{\text { a Demetrio. }}{\text { ¡Caso extraño! }}$ & & $\frac{\text { y no pasa día ninguno }}{\text { que no me acuerde de vos. }}$ \\
\hline & $\begin{array}{l}\text { Y temo desto algún daño. } \\
\text { Mil pensamientos me ofrece.) } \\
\quad \text { (El gran duque..., vv. 1420-27) }\end{array}$ & Vase. & (vv. 1868-73) \\
\hline
\end{tabular}


Moreto reproduce los versos tomados de la comedia de Lope fielmente, aunque es fácil observar que -sigo la tipología de las refundiciones propuesta por Carol B. Kirby- "han sufrido alteraciones en una palabra, el locutor y la posición en el texto" (Kirby 1006). Resulta significativo que todos los fragmentos que Moreto copió de El gran duque de Moscovia pertenecen a la secuencia que corresponde a la estancia de Demetrio en el convento. El más extenso representa la huida de Demetrio acompañado del gracioso.

\begin{tabular}{|c|c|c|c|}
\hline EMETRIO & $\begin{array}{l}\text { Desnuda presto, y colguemos } \\
\text { destos árboles, Rufino, } \\
\frac{\text { los hábitos, y el camino }}{\text { de aquella sierra tomemos. }}\end{array}$ & DEMETRIO & $\begin{array}{l}\text { Pues desnúdate y colguemos } \\
\frac{\text { destos árboles, Pepino, }}{\text { los hábitos y el camino }} \\
\text { de aquella selva tomemos. }\end{array}$ \\
\hline UFINO & $\begin{array}{l}\overline{\text { Bien dices. A Dios, capilla; }} \\
\text { a Dios, santo escapulario. }\end{array}$ & PePINO & $\begin{array}{l}\overline{\text { Bien dices. ¡Adiós, capilla!! }} \\
\text { ¿Adiós, santo escapulario! }\end{array}$ \\
\hline EMETRIO & Darte priesa es nec & DEMETRIO & Darte prisa es necesario. \\
\hline RUFino & $\begin{array}{l}\text { Tu estre } \\
\text { toda suj }\end{array}$ & PEPINO & $\frac{\text { ella me maravilla, }}{\text { eta a traidores. }}$ \\
\hline DEMETRIO & ¿No acabas? & DEMETRIO & ¿No acabas? \\
\hline RUFINO & & PEPINO & Poco me falta. \\
\hline DEMET & Cubre esa rai & DEMETRIO & Cubre esa rama más alta. \\
\hline RUFINO & 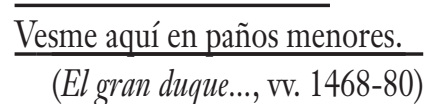 & PePINO & $\begin{array}{l}\frac{\text { Vesme aquí en paños menores. }}{\text { (vv. 1942-53) }}\end{array}$ \\
\hline
\end{tabular}

El manuscrito manifiesta una máxima fidelidad a la fuente. Por cierto, la transmisión impresa -desde la prínceps del 1651- ofrece una variante: la exclamación “¡Adiós, santo escapulario!” es sustituida por “¡Adiós cordón y rosario!”.

\section{CONCLUSIONES}

Está claro que Moreto en la jornada segunda de El príncipe perseguido quiso, por un lado, mostrar su deuda para con Lope de Vega, y por otro "su dominio del ars combinatoria" (Sáez Raposo 222) de la manera en la cual imitó pasos típicamente calderonianos. Francisco Sáez Raposo escribe al respecto de la estrategia de refundición en Moreto y sus coetáneos:

Las obras previas componían un acervo que pertenecía al grupo y no al individuo, y la labor del artista consistía, precisamente, en conocerlas, es- 
tudiarlas y superarlas estéticamente, ya que la perfección en el proceso primaba sobre la originalidad del producto final. La calidad del artista se cifraba, en buena medida, no en términos de innovación, sino en la variación de la estructura interna de un modelo al que, lógicamente, había que superar. (222)

El príncipe perseguido -comparado con la comedia fuente de Lope de Vegapermite contemplar el componente lúdico de "escribir entre amigos", tan inherente en la escritura de consuno. Los tres dramaturgos quisieron dar a la trama una mayor cohesión y a los personajes una máxima transparencia y ejemplaridad, sin perder de vista los dos modelos que pretendían enfrentar y emular para cumplir con los requisitos de la nueva pragmática teatral impuesta por las restricciones del Consejo de Castilla que tanto desolaron las actividades teatrales a partir del año 1644 . Recordemos que, por un lado, se rechazaba el desenfado de las comedias de Lope de Vega, y por otro, se quería limitar el número de comedias nuevas para que no se llenasen los patios de comedias (Cotarelo y Mori 1997, 164-65). La actitud de Moreto para con las comedias viejas fue modélica en ese sentido, cuando -cito a Sáez Raposo (213)- "guiado por el pragmatismo con el que entendía el espectáculo teatral", suprimía personajes o modificaba la relación entre ellos, dando a la trama una mayor cohesión. El manuscrito de El príncipe perseguido confirma indiscutiblemente que él fue el superintendente del texto de la comedia en su totalidad. Sus intervenciones en las jornadas de Belmonte y Martínez de Meneses, respectivamente, son puntuales y muy precisas, como el pareado que añade al aparte del rey polaco en la tercera jornada (fol. 35 r):

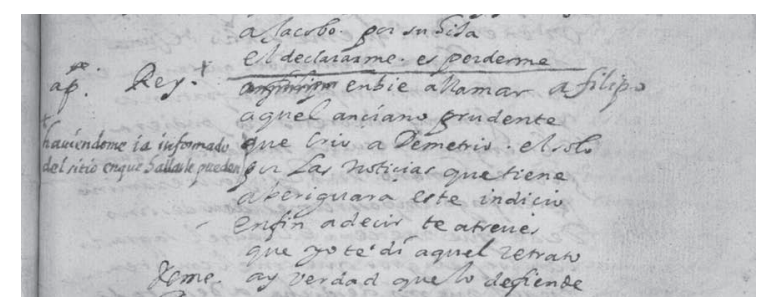

Corrían malos tiempos para los poetas que escribían para teatro. El príncipe perseguido se nos ofrece como un intento de contrarrestar las controversias en torno a la práctica teatral en la manera en la cual manifiesta los valores formativos de la comedia excediendo los límites de la ejemplaridad basada en un suceso histórico. Las didascalias implícitas aportan una competente guía de 
etiqueta cortesana. No se trata de una caso fortuito, ya que uno de sus autores, Antonio Martínez de Meneses, fue funcionario de palacio: "ayuda de guardajoyas" de la reina. Además, como ha mostrado Marta Piłat-Zuzankiewicz:

La historia del príncipe perseguido, a pesar de alterar los hechos fácticos, se inscribe perfectamente en las líneas generales de la reflexión barroca sobre el poder real. Transmite el ideal absolutista a través la elaborada construcción teatral y poética, que abunda en imágenes hábilmente insertadas en el texto de la comedia. Sus autores utilizan colecciones de emblemas como fuente rica de temas y explotan eficazmente sus posibilidades expresivas. Los adaptan a su conveniencia, desarrollando interpretaciones originales de los símbolos familiares para caracterizar a los personajes, aclarar el papel que desempeñan, expresar lecciones de carácter moral y hasta resumir la trama. Así, los emblemas revelan de manera sutil la intención de los tres ingenios y, al mismo tiempo, suponen un gran atractivo para el público capaz de comprender el sentido subyacente bajo el texto. $(2013,169)$

Resulta al menos digna de constatar la incidencia entre las Empresas políticas de Diego Saavedra Fajardo y muchas de las imágenes evocadas en El príncipe perseguido, en especial, en la jornada tercera compuesta por Martínez de Meneses. Pero, lo que salta a la vista es la intención de dejar huella de El gran duque de Moscovia de Lope de Vega y de hacer un guiño hacia La vida es sueño de Calderón. En la última jornada se nota una clara dominación calderoniana. Sin embargo, el nombre del embajador moscovita es el mismo que en la comedia fuente, Rodulfo. Su papel se limita solo a una presencia diplomática, mientras que en la comedia fuente su prototipo fue amante de una de las nueras del Gran Duque de Moscovia.

Por lo general, la colaborada explota motivos muy presentes en la producción dramática áurea; recordemos la burlesca premática del año 1637: "que en las comedias se quite el desmesurarse los embajadores con los reyes y de aquí en adelante no les valga la ley del mensajero, que ningún príncipe se finja hortelano por ninguna infanta" (Academia burlesca 60-61). En El príncipe perseguido los tres autores modificaron considerablemente la trama de la comedia fuente para que el príncipe polaco Ladislao hiciera de embajador de su padre en la corte de Moscovia y Demetrio, de jornalero en los jardines de Belflor pertenecientes al rey de Polonia. Se trataba, pues, de un ingenioso "remake o 
rifacimiento" (Cortijo 30) que los tres ingenios esperaban poder representar en la temporada que se inauguraría, como de costumbre, tras la Pascua de Resurrección. Sin embargo, "las dichas comedias no duraron más que hasta el día de Carnestolendas del año pasado de cuarenta y seis" (Shergold y Varey 288).

El príncipe perseguido es una especie de palimpsesto con un toque de ensalada, género híbrido muy popular en los ambientes cortesanos. Se trata de una obra dramática muy característica para las técnicas de reescritura teatral de todos los tiempos que, por cierto, los poetas áureos españoles supieron llevar a la perfección. Recordemos el irónico retrato de familia "de aquellos que Madrid llama «ingenios de la corte», y palacio «vulgares de la villa»" que a cada escena que oían leer, decían: "Mío es este paso, aquel estotro es mío y mío estotro, mío este episodio" (Academia burlesca 227).

\section{OBRAS CITADAS}

Academia burlesca que se bizo en Buen Retiro a la Majestad de Filipo Cuarto el Grande. Año 1637. Edición crítica, prólogo y notas de María Teresa Julio. Madrid: Iberoamericana / Frankfurt am Main: Vervuert, 2007.

Alfay, Tomás, ed. El mejor de los mejores libro que ha salido de comedias nuevas. Alcalá: A costa de Tomás Alfay, 1651. 14 de marzo de 2019. <http://bdh-rd. bne.es/viewer.vm?id=0000170838\&page $=1>$.

Alviti, Roberta. I manoscritti autografi delle commedie del "Siglo de Oro" scritte in collaborazione. Catalogo e studio. Firenze: Alinea, 2006.

Alviti, Roberta. "Moreto colaborador". "Escribir entre amigos": Agustín Moreto y el teatro barroco. Eds. María Luisa Lobato y Elena Martínez Carro. Madrid: Ayuntamiento de Madrid, 2018. 112-40.

Baczyńska, Beata. "Príncipes perseguidos y valientes damas de comedia. El espacio de la Europa del Este y del Norte en el teatro áureo español”. Aspectos actuales del hispanismo mundial: Literatura - Cultura - Lengua. Ed. Christoph Strosetzki. Berlin: Walter de Gruyter, 2018. 403-14.

Bavia, Luis de. Tercera parte de la Historia Pontificial y Católica. Madrid: Luis Sánchez, 1608.

Belmonte Bermúdez, Luis, Agustín Moreto y Antonio Martínez de Meneses. El principe perseguido. BNE, Ms. Res 81.4 de marzo de 2019. <http://bdhrd.bne.es/viewer.vm?id=0000100625\&page $=1>$.

Belmonte Bermúdez, Luis, Agustín Moreto y Antonio Martínez de Meneses. El príncipe perseguido. Texto base. Ed. Beata Baczyńska. 4 de marzo de 
2019. <http://www3.ubu.es/proteo/docs/Comedias/ClbPrincipePerseguido.pdf $>$.

Brody, Ervin C. The Demetrius Legend and its Literary Treatment in the Age of the Baroque. Cranbury: Associated University Presses, 1972.

Calderón de la Barca, Pedro. La vida es sueño. Ed. Ciriaco Morón. Madrid: Cátedra, 1982.

Cassol, Alessandro. "El ingenio compartido. Panorama de las comedias colaboradas de Moreto". Moretiana: adversa y próspera fortuna de Agustín Moreto. Eds. María Luisa Lobato y Juan Antonio Martínez Berbel. Madrid: Iberoamericana / Frankfurt am Main: Vervuert, 2008. 165-84.

Chiva Beltrán, Juan. "Triunfos en la Casa de Austria: entradas reales en la Corte de Madrid". Potestas 4 (2011): 211-28.

Cortijo, Adelaida. El príncipe perseguido de tres ingenios. Una edición modernizada. Thesis in Romance Languages. Texas Tech University: December 1998.

Cotarelo y Mori, Emilio. Bibliografía de las controversias sobre la licitud del teatro en España. Edición facsímil. Estudio preliminar de José Luis Suárez García. Granada: Universidad de Granada, 1997.

Cotarelo y Mori, Emilio. Ensayo de la vida y obras de don Pedro Calderón de la Barca. Eds. Ignacio Arellano y Juan Manuel Escudero. Madrid: Iberoamericana / Frankfurt am Main: Vervuert, 2001.

Cruickshank, Don W. Calderón de la Barca. Su carrera secular. Trad. José Luis Gil Aristu. Madrid: Gredos, 2011.

Iglesias Feijoo, Luis. "Secretos y supercherías en una comedia de Lope de Vega: El gran duque de Moscovia". Hipogrifo 5.1 (2017): 277-91.

Kirby, Carol B. "Hacia una definición precisa del término «refundición» en el teatro clásico español". Actas del X Congreso de la AIH, Barcelona 21-26 de agosto de 1989. Vol. 2. Coord. Antonio Vilanova. Barcelona: PPU, 1992. 1005-21.

Lauer, A. Robert. The restoration of monarchy. "Hados y lados bacen dichosos y desdichados". Kassel: Reichenberger, 1997.

Lobato, María Luisa. "Escribir entre amigos: hacia una morfología de la escritura dramática moretiana en colaboración”. Bulletin of Spanish Studies 92.8-10 (2015): 333-46.

Lobato, María Luisa. "Moreto, dramaturgo y empresario de teatro. Acerca de la composición y edición de algunas de sus comedias (1637-1654)". Moretiana: adversa y próspera fortuna de Agustín Moreto. Eds. María Luisa Lo- 
bato y Juan Antonio Martínez Berbel. Madrid: Iberoamericana / Frankfurt am Main: Vervuert, 2008. 15-37.

Mackenzie, Ann L. La escuela de Calderón: estudio e investigación. Liverpool: Liverpool UP, 1993.

Martínez Carro, Elena. Antonio Martínez de Meneses: vida y obra. Madrid: Fundación Universitaria Española, 2006.

Martínez Carro, Elena. "El Arte de hacer comedias colaboradas en el Siglo de Oro". "Escribir entre amigos": Agustín Moreto y el teatro barroco. Eds. María Luisa Lobato y Elena Martínez Carro. Madrid: Ayuntamiento de Madrid, 2018. 80-111.

Mosquera, Juan. Relación de la señalada y como milagrosa conquista del paterno Imperio, conseguida del Serenísimo Principe fuan Demetrio, Gran Duque de Moscovia, en el año de 1605. Valladolid: Andrés de Merchán, 1606.

Pellicer de Tovar, José. Avisos. Eds. Jean-Claude Chevalier y Lucien Clare. 3 vols. Paris: Éditions Hispaniques, 2002.

Piłat-Zuzankiewicz, Marta. "La historia del zarévich Demetrio: Una lectura emblemática de la comedia El príncipe perseguido". Teatro y poder en el Siglo de Oro. Eds. Mariela Insúa y Felix K. E. Schmelzer. Pamplona: Universidad de Navarra, 2013. 167-81.

Piłat-Zuzankiewicz, Marta. "Bestiario simbólico en la comedia El príncipe perseguido". Castilla 7 (2016): 346-65.

Piłat-Zuzankiewicz, Marta. "Imágenes verbales y emblemas escénicos en la comedia lopesca El Gran Duque de Moscovia y el Emperador perseguido". El texto dramático y las artes visuales: el teatro español del Siglo de Oro y sus herederos en los siglos XX y XXI. Eds. Urszula Aszyk, Juan Manuel Escudero Baztán y Marta Piłat-Zuzankiewicz. New York: Idea, 2017. 87-100.

Praag, J. A. Van. "Más noticias sobre la fuente de El Gran Duque de Moscovia de Lope de Vega". Bulletin Hispanique 39 (1937): 356-66.

Profeti, Maria Grazia. Per una bibliografia di fuan Pérez de Montalbán. Verona: Università degli Studi di Verona, 1976.

Rodríguez Villa, Antonio. Etiquetas de la Casa de Austria. Madrid: J. Ratés, 1913.

Sáez Raposo, Francisco. "El equilibrio imposible del teatro de Agustín Moreto entre el plagio y el canon". Presencia de la tradición en la literatura española del Siglo de Oro. Ed. Natalia Fernández Rodríguez. Barcelona: Universitat Autònoma de Barcelona, 2010. 195-225.

Skowron, Ryszard. Dyplomaci polscy w Hiszpanii w ХИІ i ХИІІ wieku. Kraków: Universitas, 1997. 
Urzáiz, Héctor, y Gema Cienfuegos. "Texto y censura de una obra atribuida a Moreto: La adúltera penitente". eHumanista. Fournal of Iberian Studies 23 (2013): 296-325. 3 de marzo de 2019. <http://www.ehumanista.ucsb.edu/ volumes/23>.

Varey, John E., y Norman D. Shergold. "Datos históricos sobre los primeros teatros de Madrid: prohibiciones de autos y comedias y sus consecuencias (1644-1651)". Bulletin Hispanique 62.3 (1960): 286-325.

Vega, Lope de. El gran duque de Moscovia y Emperador perseguido. Ed. Milagros Villar. Comedias. Parte VII. Coord. Enrico Di Pastena. Lleida: Milenio, 2008. 457-587.

Weiner, Jack. "Un episodio de la historia rusa visto por autores españoles del Siglo de Oro. El pretendiente Demetrio". Fournal of Hispanic Philology 2.3 (1978): 175-201. 